\title{
Mandibular-position sensation during sedation by administration of nitrous-oxide $\left(\mathrm{N}_{2} \mathrm{O}\right)$ gas
}

\author{
Masafumi Yoshida ${ }^{\S}$, Hironobu Araki ${ }^{\S}$, Taketo Yamaguchi ${ }^{\dagger}$, \\ Atsushi Uchida and Ichiro Nakajima \\ ${ }^{8}$ Department of Pediatric Dentistry, Nihon University, School of Dentistry, Tokyo 101-8310 \\ ${ }^{\dagger}$ Department of Dentistry, Saitama Prefecture Kaikoen, Saitama 366-0081 \\ ${ }^{\ddagger}$ Department of Dentistry, Saitama Prefecture Colony Ranzango, Saitama 355-0201
}

(Received 4 June and accepted 8 September 1999)

\begin{abstract}
Our aim was to confirm the influence of $\mathrm{N}_{2} \mathrm{O}$ gas on mandibular-position sensation. The subjects in this study were eight healthy adults. Each subject was asked to hold the reference stick for five seconds between the central tooth in his or her upper and lower jaws. Then, the reference stick was replaced by the test sticks with different thickness, each of which the subjects were again asked to hold at the same position for five seconds. The subjects were instructed to determine, based on judgement of the interincisal distance, whether the thickness of each test stick was larger or smaller than the reference stick. A series of trials was administered to each subject using all eight sizes of test sticks. We compared the ability of the subjects to discriminate mandibular position both before and after the application of a vibrating stimulus to the masticatory muscles, and before and during the administration of $\mathrm{N}_{2} \mathrm{O}$ gas. Discrimination ability was significantly decreased after the application of the vibrating stimulus. However, during the administration of $\mathrm{N}_{2} \mathrm{O}$ gas, no significant difference in discrimination ability was observed between before and after the vibrating stimulus. The results of this study indicated that $\mathrm{N}_{2} \mathrm{O}$ gas had an inhibitory effect on $\gamma$-motor neuron activity, which is presumed to be mediated to some extent through the higher central nervous system. This is the case because the $\boldsymbol{\gamma}$-motor neurons are generally activated by vibrating stimuli applied to the muscle causing decreased discrimination ability of mandibular position. Thus, we conclude that mandibularposition sensation was influenced by $\mathrm{N}_{2} \mathrm{O}$ gas during the administration of $\mathrm{N}_{2} \mathrm{O}$ gas. (J. Oral Sci. 41, 123-126, 1999)
\end{abstract}

Key words: nitrous-oxide $\left(\mathrm{N}_{2} \mathrm{O}\right)$ gas-induced sedation; mandibular position sensation; muscle spindle.

\section{Introduction}

In general, sedation by the administration of a mixture of

Correspondence to Dr. Masafumi Yoshida, Department of Pediatric Dentistry, Nihon University School of Dentistry, 1-8-13, KandaSurugadai, Chiyoda-ku, Tokyo 101-8310, Japan oxygen and $\mathrm{N}_{2} \mathrm{O}$ gas (hereafter called sedation by administration of $\mathrm{N}_{2} \mathrm{O}$ gas) is an effective method (1-5) for behavior management, and is aimed at alleviation of the patient's fear and anxiety during the dental treatment. In the field of dental surgery for the handicapped, sedation by the administration of $\mathrm{N}_{2} \mathrm{O}$ gas has been widely used during prosthesis treatment to facilitate the guiding of mandibular position or jaw movement recording. It has been reported that the administration of $\mathrm{N}_{2} \mathrm{O}$ gas raises the threshold of oral sensation in these patients, thus alleviating pain and diminishing the vomiting reflex, besides having a sedative effect (6-8). Accordingly, during the administration of $\mathrm{N}_{2} \mathrm{O}$ gas for sedation, it is expected that $\mathrm{N}_{2} \mathrm{O}$ gas influences the ability of a subject to discriminate mandibular position. However, there are no reports that examine the characteristics of mandibular position in relation to occlusion and during the administration of $\mathrm{N}_{2} \mathrm{O}$ gas.

The discrimination ability test for mandibular position (912 ) is known as a useful psychophysiological test to evaluate mandibular position sensation in humans. Morimoto et al. (912) reported that discrimination ability in this test reflects the activities of $\gamma$-motor neurons which control myesthesia by expanded acceptor of the muscle spindles of the muscles of mastication, since discrimination ability is decreased following the application of a vibrating stimulus to the muscles of mastication (9-12).

In this study, our aim was to confirm the influence of $\mathrm{N}_{2} \mathrm{O}$ gas on mandibular-position sensation during the administration of $\mathrm{N}_{2} \mathrm{O}$ gas. We examined the ability of healthy adult subjects to discriminate mandibular position both before and after the application of a vibrating stimulus to the muscles of mastication, and also before and during the administration of $\mathrm{N}_{2} \mathrm{O}$ gas.

\section{Subjects}

\section{Subjects and Methods}

The subjects in this study were eight healthy adults from the medical staff of the Pediatrics Division of the Department of Dentistry, Nihon University (four male, four female, mean age $27.4 \pm 2.7$ )

The criteria for selection of subjects were as follows. The subjects had to understand and approve of the study, had to have no prosthesis on the front teeth of the upper jaw, and had 
the individual normal occlusion with no functional abnormalities of the jaw or oral cavity.

\section{Methods}

1) Measurement of the ability to discriminate mandibular position prior to the administration of $\mathrm{N}_{2} \mathrm{O}$ gas. The subjects were seated in a dental chair in a treatment room of the Pediatrics Division. The ability to discriminate mandibular position was measured in accordance with the method of Morimoto (9-12).

The reference stick and the test sticks were made of stainless steel (Tokyo Shizai). The diameter of the reference stick was $10.0 \mathrm{~mm}$. Two groups of test sticks were used, one with larger diameters, and the other with smaller diameters than that of the reference stick. The group of sticks with smaller diameters than the reference stick had diameters of 8.0, 8.5, 9.0 and $9.5 \mathrm{~mm}$. On the other hand, the group with larger diameters than the reference had diameters of 10.5, 11.0, 11.5 and $12.0 \mathrm{~mm}$. During the measurement, the subjects' Frankfurt plane was maintained parallel to the floor. The subjects wore an eye mask to shut out visual information. The measurement procedure was as follows. First, the subject was asked to hold the reference stick for five seconds between the central tooth in their upper and lower jaws. Then the reference stick was replaced by the test sticks, each of which the subject was again asked to hold at the same position for five seconds. The subjects were instructed to determine, based on their judgement of the interincisal distance, whether the thickness of each test stick was larger or smaller than the reference stick. A series of trials was administered to each subject using all eight sizes of test sticks. The test sticks were presented randomly using a table of random numbers, and all eight sizes were presented in each session. In this study, we performed a total of ten sessions for each subject. The number of incorrect answers was divided by the total number of answers, and expressed as a percentage to obtain the "Rate of Miss Estimate" (hereafter referred to as R.M.E.), which was used to evaluate the subject's ability to discriminate mandibular position. The higher the R.M.E, the lower the ability of the subjects to discriminate mandibular position, and vice versa. The ability to discriminate mandibular position was measured in each subject before and after the application of a vibrating stimulus using a vibratingstimulus generating devise (Heiwa Denshi, TMT-18 type). The frequency of the vibrating stimulus was $100 \mathrm{~Hz}$. The measurement was performed immediately after application of the vibrating stimulus for $3 \mathrm{~min}$ at the center of the mandible.

2) Measurement of the ability to discriminate mandibular position during the administration of $\mathrm{N}_{2} \mathrm{O}$ gas (see Fig. 1)

This experiment was performed one week after the previous series of experiments, while administering $\mathrm{N}_{2} \mathrm{O}$ gas for sedation of the patients. With the exception of the gas presentation, the measurement methods and procedures for these tests were identical to those employed for the previous series of experiments. The measurements were begun when an optimally-sedated state appeared. Table 1 describes the optimally-sedated state (13).
Fig. 1 Measurement of the ability to discriminate mandibular position during the administration of $\mathrm{N}_{2} \mathrm{O}$ gas.

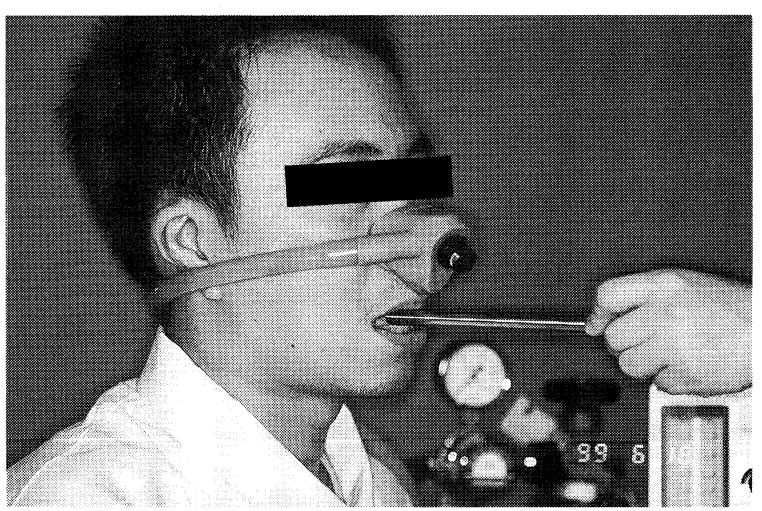

Table 1 Optimally-sedated state during the administration of $\mathrm{N}_{2} \mathrm{O}$ gas

Objection symptom

1) Subjects can communicate consciously.

2) Subjects feel relaxed and comfortable.

3) The amount of nictitation is decreased.

Subjective symptoms

1) A feeling of lassitude and ligte intoxication.

2) A sense of great happiness.

3) Subjejects feel a sense of warwth and are not aware of their surroundings.

A continuous outflow-type absorption sedative device, the Psychorich T-70 (Sekimura), was employed for the administration of a mixture of $\mathrm{N}_{2} \mathrm{O}$ gas and oxygen. The subjects wore nose masks and inhaled the gas mixture of oxygen: $\mathrm{N}_{2} \mathrm{O}$ gas, 60:40. In consideration of the normal ventilatory volume per minute in healthy adults, the flow rate of the gas mixture was set at approximately $6-8 \mathrm{~L} / \mathrm{min}$.

\section{Statistical Methods}

Paired $t$-tests were used to compare the R.M.E. before and after the application of the vibrating stimulus in the absence of administration of $\mathrm{N}_{2} \mathrm{O}$ gas, and also the R.M.E. before and after the application of the vibrating stimulus during the administration of $\mathrm{N}_{2} \mathrm{O}$ gas.

\section{Results}

Table 2 shows the results of the evaluation of the ability of the subjects to discriminate mandibular position in the absence of the administration of $\mathrm{N}_{2} \mathrm{O}$ gas. For the interincisal distance of $9.5 \mathrm{~mm}$, the R.M.E. after the application of the vibrating stimulus was significantly higher than that before the application of the vibrating stimulus $(\mathrm{p}<0.01)$. However, no significant differences in R.M.E. between before and after the application of vibrating stimulus were observed for the other interincisal distances. Thus, the discrimination ability at the interincisal distance of $9.5 \mathrm{~mm}$, smaller than that of the $10.0 \mathrm{~mm}$ reference, was decreased after the application of a vibrating stimulus compared to before its application.

Table 3 shows the evaluation results of the ability to discriminate mandibular position during the administration of $\mathrm{N}_{2} \mathrm{O}$ gas. In this study, the optimally-sedated state was observed 
Table 2 Comparison between before and after the vibrating stimulus in the mean Rate of Miss Estimate (R.M.E.) of the interincisal distance (no $\mathrm{N}_{2} \mathrm{O}$ inhalation period)

(The unit : \%)

\begin{tabular}{|c|c|c|c|c|c|c|c|c|c|}
\hline The interincisal distance $(\mathrm{mm})$ & 8.0 & 8.5 & 9.0 & 9.5 & 10.0 (The reference stick ) & 10.5 & 11.0 & 11.5 & 12.0 \\
\hline Before the vibrating stimulus & 0 & 0 & 0 & $1.3 \pm 1.57$ & & $4.0 \pm 1.9$ & $0.3 \pm 0.7$ & 0 & 0 \\
\hline After the vibrating stimulus & 0 & 0 & 0 & $4.3 \pm 1.7$ & & $3.8 \pm 1.7$ & $0.5 \pm 0.9$ & 0 & 0 \\
\hline
\end{tabular}

**:p<0.01 mean \pm S.D.

Table 3 Comparison between before and after the vibrating stimulus in the mean R.M.E. of the interincisal distance $\left(\mathrm{N}_{2} \mathrm{O}\right.$ inhalation period)

(The unit : \%)

\begin{tabular}{cccccccccc}
\hline \hline The interincisal distance $(\mathrm{mm})$ & 8.0 & 8.5 & 9.0 & 9.5 & 10.0 (The reference stick) & 10.5 & 11.0 & 11.5 & 12.0 \\
\hline Before the vibrating stimulus & 0 & 0 & 0 & $0.5 \pm 1.4$ & $9.8 \pm 0.7$ \\
After the vibrating stimulus & 0 & 0 & 0 & 0 & $7.3 \pm 1.8$ & $2.0 \pm 2.1$ \\
\hline
\end{tabular}

**:p<0.01 *:p<0.05 mean \pm S.D.

in all subjects approximately five minutes after commencing the administration of $\mathrm{N}_{2} \mathrm{O}$ gas. The R.M.E. for the interincisal distances of $10.5,11.0$ and $11.5 \mathrm{~mm}$ were significantly lower after application of the vibrating stimulus than before vibration $(p<0.01)$. However, no significant difference in R.M.E. between before and after the application of the vibrating stimulus was observed for other interincisal distances. Thus, the lowering of discrimination ability of the subjects for the interincisal distances of $10.5,11.0$ and $11.5 \mathrm{~mm}$, higher than the $10.0 \mathrm{~mm}$ reference distance, was suppressed after application of the vibrating stimulus compared to that before its application.

\section{Discussion}

Prior to the administration of $\mathrm{N}_{2} \mathrm{O}$ gas, discrimination ability was significantly decreased after the application of vibrating stimulus for the interincisal distance of $9.5 \mathrm{~mm}$, compared to before the vibration stimulus presentation. However, no significant difference in discrimination ability was observed for the other interincisal distances. Thus, without $\mathrm{N}_{2} \mathrm{O}$ gas, discrimination ability was decreased after application of the vibrating stimulus for the interincisal distance lower than the reference. Under these conditions, the muscle spindles were not expanded at the interincisal distance of $9.5 \mathrm{~mm}$. When the vibrating stimulus was applied to the unexpanded muscle spindle, the $\gamma$-motor neurons became persistently excited. It was believed that this is the reason for the discrimination ability of mandibular position to have decreased.

Morimoto et al. (10) have already reported that in healthy subjects, the ability to discriminate mandibular position was decreased for interincisal distance smallers than the reference, following the application of a vibrating stimulus of approximately $100 \mathrm{~Hz}$ from the skin surface to the muscle spindles of the occlusal muscles. The results of this study were consistent with Morimoto's results.

Meanwhile, during the administration of $\mathrm{N}_{2} \mathrm{O}$ gas, the lowering of discrimination ability was significantly suppressed after application of the vibrating stimulus compared to before vibration, for interincisal distances of $10.5,11.0$ and $11.5 \mathrm{~mm}$.
However, no significant differences in discrimination ability were observed between before and after the vibrating stimulus for other interincisal distances. During the administration of $\mathrm{N}_{2} \mathrm{O}$ gas, the discrimination ability of mandibular position was influenced for interincisal distances which were higher than the reference. Morimoto et al. $(9,10)$ reported that the muscle spindles expanded and $\gamma$-motor neurons became active when subjects open their mouths bigger than the reference for the interincisal distance. In this study, the discrimination ability was not influenced by the vibrating stimulus for the interincisal distances of $10.5,11.0$ and $11.5 \mathrm{~mm}$ before the administration of $\mathrm{N}_{2} \mathrm{O}$ gas. However, the results of this study indicate that during the administration of $\mathrm{N}_{2} \mathrm{O}$ gas, the lowering of discrimination ability is suppressed following the application of the vibrating stimulus even if the muscle spindles are expanded. The aforementioned observations indicate that the characteristics of the ability to discriminate mandibular position were essentially different under the two conditions. Kaufman et al. (14) reported that $\mathrm{N}_{2} \mathrm{O}$ gas inhibits motor neuron excitation at the center nervous system level, since the muscle discharge amplitude evoked by $\mathrm{H}$-reflection of the peripheral muscles in patients with cerebral palsy was decreased during the administration of $\mathrm{N}_{2} \mathrm{O}$ gas.

We consider that the results of this study indicate that $\mathrm{N}_{2} \mathrm{O}$ gas has an inhibitory effect on $\gamma$-motor neuron excitation to some extent through the upper centers, since the $\gamma$-motor neuron is a centrifugal neuron. Thus, our data suggest that the muscle sensation of the masticatory muscles is influenced by $\mathrm{N}_{2} \mathrm{O}$ gas during the administration of $\mathrm{N}_{2} \mathrm{O}$ gas. Accordingly, we conclude that sedation produced by the administration of $\mathrm{N}_{2} \mathrm{O}$ gas should not be used for the guiding of mandibular position in prosthesis treatment in the field of dental surgery for the handicapped.

\section{References}

1. Kubota, Y. (1972) Psychosedation. Kokubyo Gakkai Zasshi 39, 534 (in Japanese)

2. Everett, G.B. and Allen, G.D. (1971) Simultaneous 
evaluation of cardiorespiratory and analgesic effects of nitrous oxide-oxygen inhalation analgesia. J. Am. Dent. Assoc. 83, 129-133

3. Murase, M., Takai, H., Sato, M., Kokita, Y., Shima, K., Kokiwa, N., Hasegawa, S., Yatabe, Y., Ohashi, Y., Kanri, T., Suzuki, Y., Nomura, O., Sekiyama, S., Komoribayashi, N., Seki, S., Mori, Y., Tomita, K., Shinya, N., Murakami, T., Goda, S., Fukushima, K., Sasaki, M., Tsubahara, S., Yuki, K. and Hayatsu, Y. (1975) Study on clinical effect of $30 \%$ nitrous oxide and oxygen mixture (anesoxin-30) in oral surgery. Nippon Koku Geka Gakkai Zasshi 21, 649-661(in Japanese)

4. Ito, H. (1975) A study on analgesic effect of inhalant sedation with nitrous oxide and oxygen. Nihon Shika Masui Gakkai Zasshi 3, 15- 33 (in Japanese)

5. Ruben, H. (1966) Nitrous oxide analgesia for dental patients. Acta Anaesthsiol. Scand. Suppl. 25, 419-420

6. Sano, H. (1977) Infuluence of intensity-varied electrical stimulation of a tooth and $30 \%-\mathrm{N}_{2} \mathrm{O}$ premixed gas inhalation on somotosensory evoked potentials (SEPs). Nihon Shika Masui Gakkai Zasshi 5, 9-21(in Japanese)

7. Kondo, T. (1986) Somatosensory evoked potentials (SEP) during electrical tooth stimulation in regular and random intervals and the effects of inhalation of $30 \%$ $\mathrm{N}_{2} \mathrm{O}$ in oxygen. Nihon Shika Masui Gakkai Zasshi 14, 181-195 (in Japanese)

8. Ayuse, T. (1988) Habituation of pain perception and effects of inhalation of $30 \% \mathrm{~N}_{2} \mathrm{O}$ in oxygen. Nihon Shika Masui Gakkai Zasshi 16, 245-263 (in Japanese)

9. Morimoto, T., Hamada, T. and Kawamura, Y. (1983) Alteration in directional specificity of interdental dimension discrimination with the degree of mouth opening. J. Oral Rehabil. 10, 335-342

10. Morimoto, T. and Kawamura, Y. (1976) Conditioningeffect of vibratory stimulation on dimension discrimination of objects held between human tooth arches. Arch. Oral Boil. 21, 219-220

11. Morimoto, T., Takebe, H., Hamada, T. and Kawamura, Y. (1981) Oral kinesthesia in patients with Duchenne muscular dystrophy. J. Neurol. Sci. 49, 285-291

12. Morimoto, T., Ozaki, M., Yoshimura, Y. and Kawamura, Y. (1979) Effects of the interpolated vibratory stimulation on the interdental dimension discrimination in normal and joint defect subjects. J. Dent. Res. 58, 560-567

13. Roberts, G.J. (1991) Part 1. Local analgesia and inhalation sedation. In A colour atlas of dental analgesia \& sedation. Roberts, G.J. and Rosenbaum, N.L., Wolfe Publishing, Aylesbury, 71-99

14. Kaufman, E., Meyer, S., Wolnerman, J. S. and Gilai, A.N. (1991) Transient suppression of involuntary movements in cerebral palsy patients during dental treatment. Anesth. Prog. 38, 200-205 